\title{
Evaluation of extension of breast screening to women aged 65-70 in England using screening performance measures
}

\author{
RL Bennett ${ }^{*,}$, RG Blanks' and SM Moss' \\ 'Cancer Screening Evaluation Unit, Institute of Cancer Research, 15 Cotswold Road, Sutton, Surrey SM2 5NG, UK
}

\begin{abstract}
The objective of this study was to investigate screening performance measures in the English screening units that began inviting women aged 65-70 between I April 200 I and I April 2004. We analysed results after each unit commenced inviting women aged 65-70. In addition, we analysed data from units that invited this age group for a second time between I April 2004 and 3I March 2007. Results for women aged 65-70 were compared to women aged 50-64 and 60-64. Average uptake was 72.8\% for women aged $65-70$ and $76.7 \%$ for women aged $50-64$. For women screened within the last 5 years, uptake was $88.7 \%$ for older women and $89.1 \%$ for younger women. For women previously screened within 5 years the invasive cancer detection rate was $17 \%$ higher in the 65-70 age group than in the 60-64 age group. The rates of recall to assessment and PPV were 3.5 and $27.6 \%$ in women aged 65-70 and 3.4 and $24.6 \%$ in women aged 50-64 respectively. These results suggest that, as in the earlier demonstration studies, uptake rates remain high in older women, and many more older women attend following an invitation than had previously selfreferred. The cancer detection rate is higher in this older age group, whereas rates of recall are generally similar to those in younger women; consequently the PPV is also higher in older women.

British Journal of Cancer (2009) I 00, 1043- 1047. doi: I0.1038/sj.bjc.660498 I www.bjcancer.com
\end{abstract}

Published online 10 March 2009

(c) 2009 Cancer Research UK

Keywords: breast cancer; screening; older women

When the UK NHS Breast Screening Programme (NHSBSP) began in 1988, women aged between 50 and 64 years were invited to three yearly screening, whereas older women were able to selfrefer. (Forrest, 1986). A survey in 1995 showed that in many countries women aged up to 69 or 70 are invited to screening (Shapiro et al, 1998). Although breast screening is acknowledged as efficacious for women aged 50-69, when the UK programme commenced there was concern regarding possible lower uptake and reduced cost-effectiveness in older women (Moss et al, 2001). More recently, results from three demonstration studies in England, in which invitations were extended to women aged 65-69, suggested that older women who have previously been routinely screened by the programme had similar uptake patterns to younger women, and screening these women was estimated to be as cost-effective as for the 50-64 age group (Moss et al, 2001). As a result of these studies, the expansion of the programme to invite women up to the age of 70 was announced in the NHS Cancer Plan in 2000 (Department of Health, 2000). The publication also announced the introduction of two-view mammography at the incident screen. English units were expected to have begun this by 2003 and to have started including women aged 65-70 into the routine invitation system by the end of 2004.

The aim of this study was to investigate if the implementation of this policy change gave similar results to those from the demonstration studies. We analysed results from those units that

*Correspondence: RL Bennett; E-mail: rachel.bennett@icr.ac.uk Received 22 October 2008; revised 12 February 2009; accepted 17 February 2009; published online 10 March 2009 began inviting the 65-70 age group between 1 April 2001 and 1 April 2004 and therefore had completed at least a full 3-year screening round by 31 March 2007.

\section{METHODS}

Between April 2001 and April 2004, 36 units in England began inviting women aged between 65 and 70, in addition to women aged 50-64, to screening. These units were distributed throughout England and represented approximately $40 \%$ of both the total number of units and of the target population of the screening programme.

Aggregated information on activity and outcomes is reported annually by screening units on statutory KC62 returns, which report on specific cohorts of women; for example data for 2002 relate to women screened between 1 April 2001 and 31 March 2002.

As the majority of women aged 65-70 will have been previously screened, performance measures (rates of recall, cancer detection, benign biopsy and non-operative diagnosis of cancer) were calculated for women who had previously been screened by the programme both within the last 5 years and more than 5 years previously. Uptake of invitation was calculated for all women according to previous screening history. Results for the 65-70 age group were compared with those for both the previous target age range $(50-64)$ and the oldest age group in that range (60-64). The statistical significance of these comparisons was tested using a two-sample test of proportions in Stata version 9.2.

We examined data for each unit for the first 3 complete years after they commenced inviting the 50-70 age group. For example, in a unit beginning to invite the 65-70 age group in August 2003, 
we used data for the period 1 April 2004 to 31 March 2007. To estimate the increase in the number of older women being screened due to the expansion of invitation to the 65-70 age group, we compared the number of women aged 65-70 screened in this 3-year period with the number of women who self-referred in the 65-69 age group (because data for age 70 were not available before 2003) in the 3 complete years prior to each unit inviting older women.

During initial invitation of older women (round 1), those aged between 65 and 67 will have been invited to screening 3 years previously, and are likely to form the majority of women screened within the last 5 years, whereas those aged $68-70$ are likely not to have been invited for 6 years and will form the majority of women last screened more than 5 years previously. In addition, for the 23 units that began the expansion between April 2001 and April 2003, we examined data as they began the re-invitation of the 65-70 age group (round 2) to screening, when all women will have been invited to screening within the last 3 years. Figure 1 shows the previous screening history of women aged $65-70$ at both rounds 1 and 2 assuming that before the policy change women had received their last invitation between ages 62 and 64.9 years.

In 2004, an annex was added to the data return providing anonymised individual-based pathology data for all screendetected cancers. The quality of these data was poor in the first year, and we therefore used data from 2005 onwards. Data on all cancers detected by the screening units during the 3-year period between 1 April 2004 and 31 March 2007 (KC62 year, 2005-2007) were used to calculate the Nottingham Prognostic Index (NPI) in order to compare the prognosis for the 65-70 age group with that of younger women. The index was derived from a series of women with primary breast cancer and uses lymph node status, tumour size and pathological grade. From this series three subsets of patients were identified; those with a good prognosis, a moderate prognosis and a poor prognosis (survival at 10 years after diagnosis was 88,60 and $18 \%$ respectively) (Blamey, 2002).

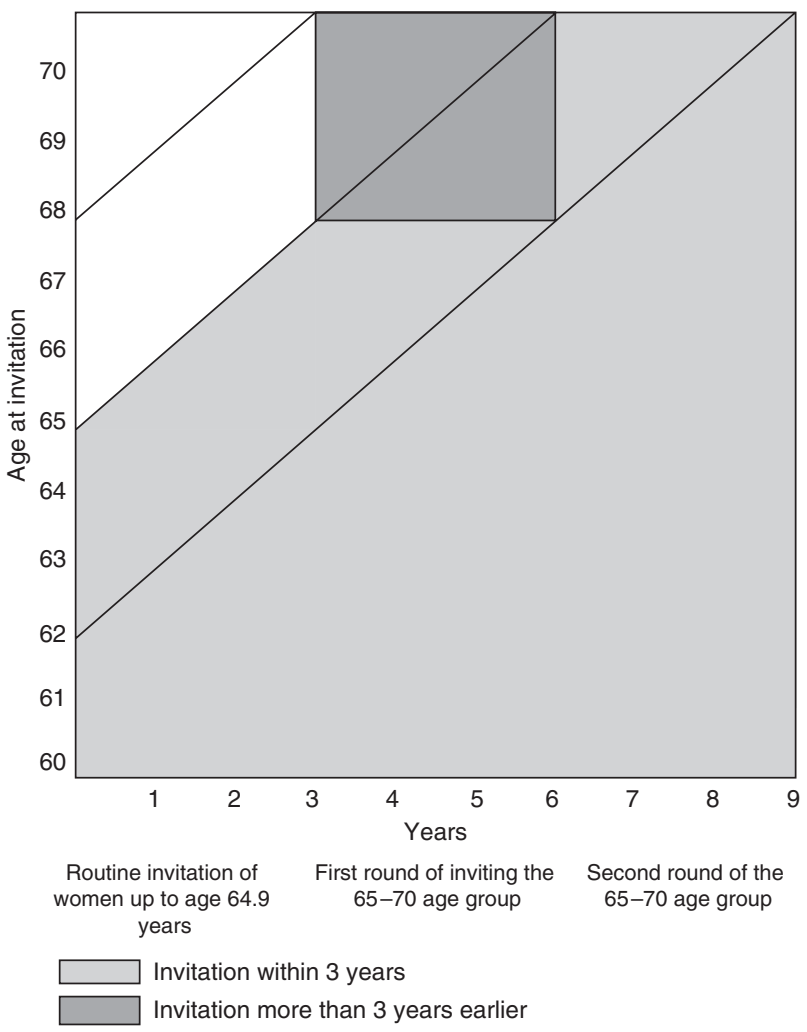

Figure I Age at invitation and previous screening history of older women in units commencing invitation of 65-70 age group.

\section{RESULTS}

The dates when the 36 units began inviting women up to the age of 70 are shown in Figure 2. Units commencing between April 2001 and April 2003 began re-inviting the 65-70 age group between April 2004 and April 2006. Although two units commenced inviting the 65-70 age group in April 2001, the majority of the units began in 2003. By this time approximately $60 \%$ of the units had already started taking two views at the incident screen, and a further third started at the same time; therefore most women invited by the units would have had two mammographic views taken.

A total of 516213 women aged $65-70$ were invited to screening in the first round, and 201589 in the second round. Uptake for this age group was $72.8 \%$ at both rounds. Average uptake in the two rounds was $76.7 \%$, and $76.8 \%$ for the $50-64$ and $60-64$ age groups respectively. The number of older women screened in the first round was more than five times the number (67546, aged 65-69) who self-referred in these units in the 3 years prior to them beginning to invite older women.

Table 1 shows the uptake rates by age group, invitation type and round. A percentage of women aged 65-70 were invited for the first time. (Reasons for this may include women moving to the UK, previously screened women moving to a new area whose screening history was not forwarded from their old area and women previously recorded as ineligible now being invited). At the first round, the 65-70 age group demonstrated similar patterns of uptake to women aged 60-64, except for those women whose last screen was more than 5 years ago, whose uptake was higher (66.6 vs $46.0 \%)$. The results may reflect the fact that the older women in the 65-70 age group would not have been invited for 6 years. A proportion of older women in this age group will have been screened more recently as a result of selfreferral, and this may explain why more than half of the 65-70 age group had been screened within the last 5 years. At the second round, for women screened more than 5 years previously, the older age group showed a similar pattern of uptake to the 60-64 age group; all these women will have been non-attenders at their last invitation.

The overall recall to assessment rate in the $65-70$ age group was $3.4 \%$ for women screened within the last 5 years and was similar to the 60-64 age group at both rounds (Table 2). For women screened more than 5 years previously the rate was $5.2 \%$ in the older age group. This was similar to rates in the younger age groups at the first round but at the second round rates decreased in both the 50-64 and 60-64 age groups but remained higher in the $65-70$ age group.

The average invasive cancer detection rate in the 65-70 age group was 7.6 per 1000 in women screened within the last 5 years and 12.0 per 1000 in women screened at a longer screening interval (Table 2). Both were significantly $(P<0.001)$ higher than rates in the 60-64 age group (6.5 per 1000 women screened and 8.9 per 1000 women screened respectively).

The in situ cancer detection rate was similar in the 60-64 and $65-70$ age groups; 1.6 per 1000 women screened versus 1.7 per 1000 women screened for women screened within 5 years and 2.2 per 1000 women screened versus 2.6 per 1000 women screened in women screened more than 5 years ago (Table 2).

In women screened within the last 5 years the small $(<15 \mathrm{~mm})$ invasive cancer detection rate was significantly $(P<0.001)$ higher in the 65-70 age group than the 60-64 age group (4.4 per 1000 women screened $v s 3.7$ per 1000 women screened) (Table 2). Rates were also higher in older women screened more than 5 years ago but the rates decreased from the first to the second round in all age groups (unlike in women screened within the last 5 years where they remained stable).

The percentage of small $(<15 \mathrm{~mm})$ invasive cancers was $55 \%$ in the $50-64$ age group, $57 \%$ in the $60-64$ age group and $58 \%$ in the 


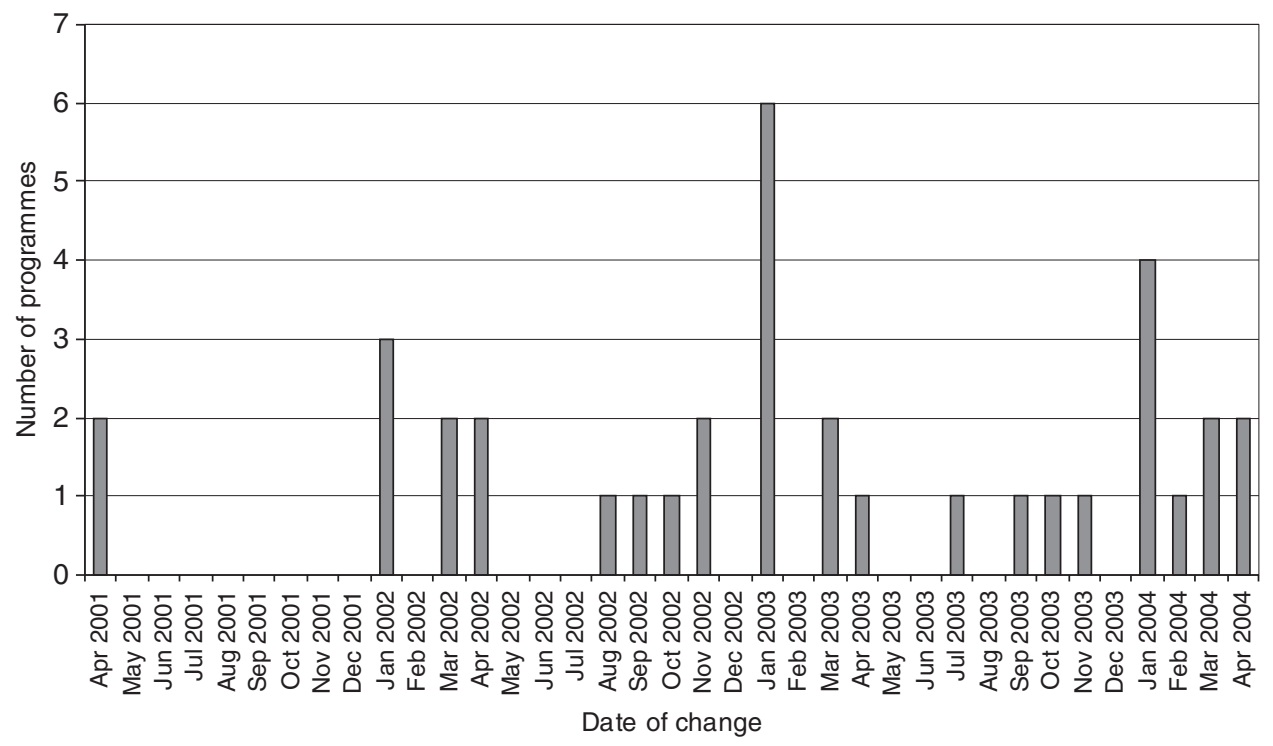

Figure 2 Start date for programmes commencing to invite 65-70 age group between April 200I and April 2004.

Table I Uptake of screening according to invitation type and screening round

\begin{tabular}{|c|c|c|c|c|c|c|}
\hline \multirow[b]{2}{*}{$\begin{array}{l}\text { Invitation } \\
\text { type }\end{array}$} & \multicolumn{2}{|c|}{$\begin{array}{c}\text { First round of } \\
\text { inviting } 65-70 \\
\text { age group }\end{array}$} & \multicolumn{2}{|c|}{$\begin{array}{l}\text { Second round of } \\
\text { inviting } 65-70 \\
\text { age group }\end{array}$} & \multicolumn{2}{|c|}{ Overall } \\
\hline & Invited & $\begin{array}{c}\text { Uptake } \\
\text { (\%) }\end{array}$ & Invited & $\begin{array}{c}\text { Uptake } \\
\text { (\%) }\end{array}$ & Invited & $\begin{array}{c}\text { Uptake } \\
(\%)\end{array}$ \\
\hline \multicolumn{7}{|c|}{ First invitation } \\
\hline $50-64$ & 360432 & 74.0 & 130075 & 73.0 & 490507 & 73.7 \\
\hline $60-64$ & 7836 & 35.3 & 2713 & 36.8 & 10549 & 35.7 \\
\hline $65-70$ & 8209 & 31.7 & 2269 & 30.1 & 10478 & 31.4 \\
\hline \multicolumn{7}{|c|}{ Previously invited never screened } \\
\hline $50-64$ & |9477| & 21.0 & 77044 & 19.7 & 271815 & 20.6 \\
\hline $60-64$ & 50689 & 10.1 & 20590 & 9.6 & 71279 & 9.9 \\
\hline $65-70$ & 50349 & 8.5 & 18599 & 6.6 & 68948 & 8.0 \\
\hline \multicolumn{7}{|c|}{ Previous screen $\leqslant 5$ years } \\
\hline $50-64$ & | 244889 & 89.3 & 471812 & 88.6 & $171670 \mid$ & 89.1 \\
\hline $60-64$ & 434364 & 89.8 & 175411 & 89.5 & 609775 & 89.7 \\
\hline $65-70$ & 288718 & 88.9 & 147893 & 88.3 & 436611 & 88.7 \\
\hline \multicolumn{7}{|c|}{ Previous screen $>5$ years } \\
\hline $50-64$ & 128460 & 51.5 & 50399 & 49.9 & 178859 & 51.1 \\
\hline $60-64$ & 61404 & 46.0 & 25054 & 44.9 & 86458 & 45.7 \\
\hline $65-70$ & 168937 & 66.6 & 32828 & 43.7 & 201765 & 62.8 \\
\hline
\end{tabular}

$65-70$ age group for women screened within the last 5 years. For women screened more than 5 years previously the percentages were 53,52 and $51 \%$ respectively.

The positive predictive value of recall to assessment (PPV) was significantly $(P<0.001)$ higher in the $65-70$ age group than the $60-64$ age group for women screened both within the last 5 years $(27.6 v s$ 24.6\%) and those with a longer screening interval (28.3 vs $21.8 \%)$.

Rates of benign surgical biopsies for the 65-70 age group were $0.06 \%$ in women screened within 5 years and $0.10 \%$ for women screened more than 5 years previously. These were similar to those in the 50-64 and 60-64 age groups. The overall percentages of cancers with a non-operative diagnosis of cancer were also similar between the 60-64 and 65-70 age groups with $95.1 \%$ of older women screened within 5 years receiving a non-operative diagnosis of cancer and $94.8 \%$ who were screened more than 5 year previously.

Table 3 shows the proportion of cancers (including those with an unknown lymph node status) falling into each of the diagnostic categories of the NPI. The proportion of cancers in older women with a good prognosis was similar to that in the 60-64 age group.

\section{DISCUSSION}

Although units included in this study began including women aged 65-70 in the invitation system between April 2001 and April 2004, most began inviting older women after December 2002; results from the first invitation of the 65-70 age group therefore mainly represented activity between 1 April 2003 and 31 March 2007, whereas the results for the re-invitation of the 65-70 age group were based on units that began earlier and represent activity mainly between 1 April 2005 and 31 March 2007. The re-invitation of the age group only represents a full 3 -year screening round for 2 out of the 23 units. However, average performance measures in England between April 2003 and March 2007 were stable apart from recall rate which has decreased.

The results of this study showed that although uptake was lower in women aged 65-70 than in women aged both 50-64 and 60-64 for all age groups, it was more than the $70 \%$ minimum target set by the programme (NHS Breast Screening Programme, 2005). The results are similar to those from the English demonstration studies and results from screening programmes in both Denmark and the Netherlands, which also invite women aged 65-69 and report more than $70 \%$ of women accepting an invitation to screening (Sarkeala et al, 2004).

The invasive cancer detection rate in women screened both within 5 years and more than 5 years previously and the small invasive cancer detection rate in women screened more than 5 years ago both decreased between the first and second rounds. At the first round, in the 50-64 age group, these rates were higher than the English average and thus results at the second round, although based on fewer data, may better reflect rates as units continue to invite women aged 65-70. 
Table 2 Rates of recall to assessment and cancer detection by screening round, previous screening history and age group

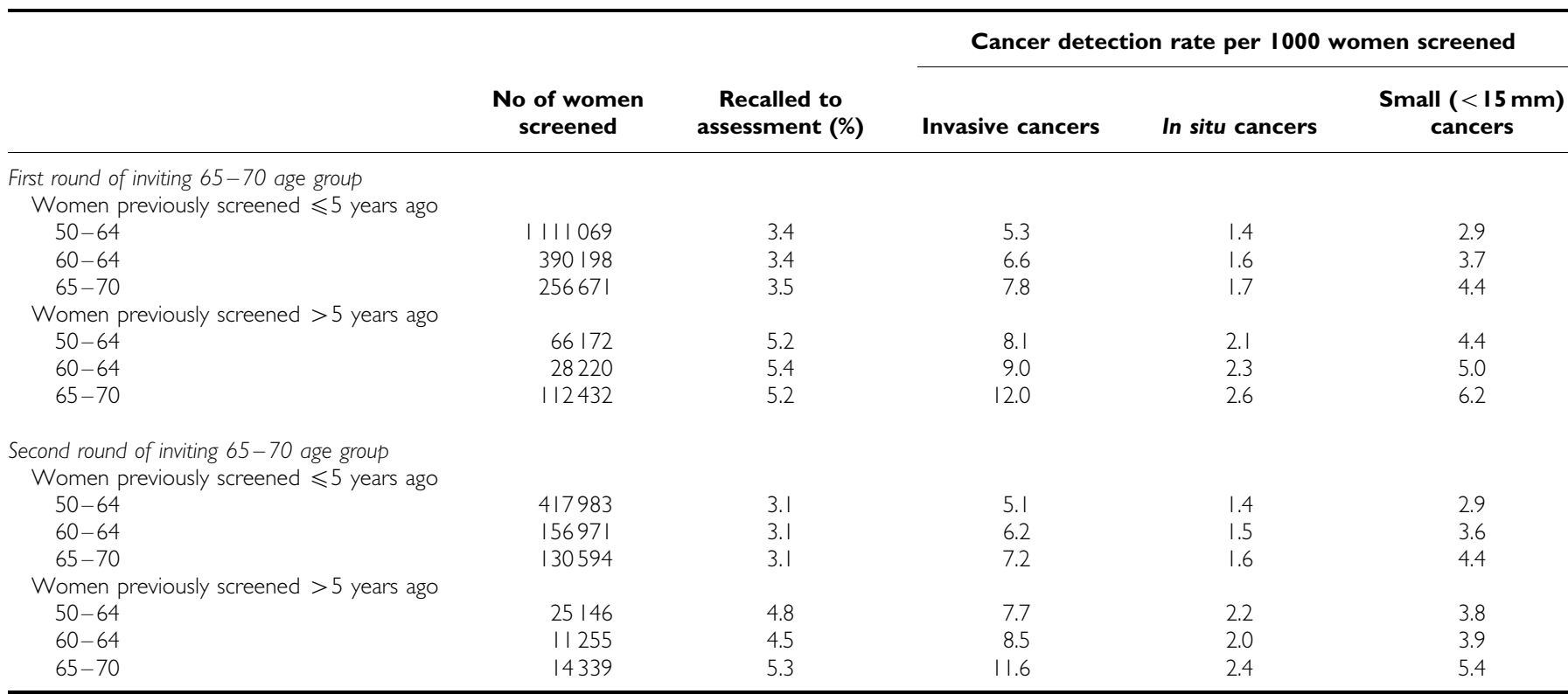

Table 3 NPI (prevalent and incident screens combined) by age group

\begin{tabular}{|c|c|c|c|c|c|c|c|c|c|}
\hline & \multicolumn{2}{|c|}{ Good } & \multicolumn{2}{|c|}{ Moderate } & \multicolumn{2}{|c|}{ Poor } & \multicolumn{2}{|c|}{ Not known } & \multirow[b]{2}{*}{ Tota } \\
\hline & No & $\%$ & No & $\%$ & No & $\%$ & No & $\%$ & \\
\hline $50-54$ & 1313 & 55 & 891 & 37 & 136 & 6 & 65 & 3 & 2405 \\
\hline $55-59$ & 1503 & 53 & 1058 & 37 & 192 & 7 & 89 & 3 & 2842 \\
\hline $60-64$ & 1715 & 58 & 1007 & 34 & 147 & 5 & 112 & 4 & 2981 \\
\hline $65-70$ & 2023 & 59 & 1110 & 32 & 165 & 5 & 128 & 4 & 3426 \\
\hline
\end{tabular}

As in the demonstration studies, the rise in breast cancer incidence with age was reflected in the increased invasive cancer detection rate in the 65-70 age group. However rates of both small and overall invasive cancers in all age groups were higher in this study than in the demonstration studies, probably as a result of units now using two-view mammography at all incident screens. However, a slower rate of tumour growth is suggested by an increased mean sojourn time in the older age group (Tabar et al, 2000), this may suggest an increasing chance of overdiagnosis in the older age group due to increasing all-cause mortality.

As a result of the increased invasive cancer detection rate in the 65-70 age group, and low rates of recall to assessment, the PPV increased in older women. However, results from further units will be watched with interest. The demonstration studies showed a lower rate of recall in the older age group, although the Netherlands, which has always invited the 50-70 age group, has shown an increase in recall rate, as well as PPV and cancer detection, with increasing age (National Evaluation Team for Breast Cancer Screening, 2005).

In 2002, an IARC working group concluded, given the evidence from randomised controlled trials, that breast screening programmes should target women aged 50-69 (IARC Working Group on the Evaluation of Cancer-Preventive Strategies, 2002). Some countries now routinely invite women aged over 70; women are invited up to 74 years in Sweden and 75 years in the Netherlands. In England, the recent publication of the Cancer Reform Strategy announced the further expansion of the NHSBSP to women aged 47-73 years (Department of Health, 2007). The results from this observational study of extending the upper age limit to 70 have shown that although women above the age of invitation are able to self-refer, the number doing so is far fewer than the number of women in the same age group who attend following an invitation. Consequently, current rates of self-referral in women aged 71-73 should not be used to predict future uptake in this age group. The effect on resources of the further extension of the programme is likely to be considerable if uptake for both the 71-73 and 47-49 age groups is similar to the $50-70$ age group.

\section{Calculation of the NPI}

The index was calculated using the formula: size $(\mathrm{cm}) \times 0.2+$ lymph node status $(1-3)+$ grade (Haybittle et al, 1982). An index using a revised formula (size $(\mathrm{cm}) \times 0.42+$ grade $\times 0.78)$ was calculated for cancers with unknown lymph node status (The Breast Screening Frequency Trial Group, 2002).

\section{ACKNOWLEDGEMENTS}

We are grateful to the NHS Cancer Screening Programmes for providing data for this study. This work forms part of a programme of independent research by the CSEU, which is funded by the Policy Research Programme of the Department of Health. The views are those of the authors and not necessarily those of the Department of Health.

\section{REFERENCES}

Blamey RW (2002) Estimation of prognosis of the individual with primary breast cancer and its applications. Scand J Surg 91: 273-278
Department of Health (2000) The NHS Cancer Plan. A Plan for Investment. A Plan for Reform. Department of Health: London 
Department of Health (2007) Cancer Reform Strategy. Department of Health: London

Forrest APM (1986) Breast Cancer Screening: Report to the Health Ministers of England, Wales, Scotland and Northern Ireland. HMSO: London

Haybittle JL, Blamey RW, Elston CW, Johnson J, Doyle PJ, Campbell FC, Nicholson RI, Griffiths K (1982) A prognostic index in primary breast cancer. Br J Cancer 45: $361-366$

IARC Working Group on the Evaluation of Cancer-Preventive Strategies (2002) IARC Handbooks of Cancer Prevention: Breast Cancer Screening. IARC: Lyon

Moss SM, Brown J, Garvican L, Coleman DA, Johns LE, Blanks RG, Rubin G, Oswald J, Page A, Evans A, Gamble P, Wilson R, Lee L, Liston J, Sturdy L, Sutton G, Wardman G, Patnick J, Winder R (2001) Routine breast screening for women aged 65-69: results from evaluation of the demonstration sites. $\mathrm{Br} J$ Cancer 85: $1289-1294$

National Evaluation Team for Breast Cancer Screening (2005) Landelijke evaluatie van bevolkingsonderzoek naar borstkanker in Nederland. Erasmus MC: Rotterdam
NHS Breast Screening Programme (2005) Consolidated Guidance on Standards for the NHS Breast Screening Programme. NHSBSP Publications: Sheffield

Sarkeala T, Anttila A, Forsman H, Luostarinen T, Saarenmaa I, Hakama M (2004) Process indicators from ten centres in the Finnish breast cancer screening programme from 1991 to 2000. Eur J Cancer 40: 2116-2125

Shapiro S, Coleman EA, Broeders M, Codd M, de Koning H, Fracheboud J, Moss S, Paci E, Stachenko S, Ballard-Barbash R (1998) Breast cancer screening programmes in 22 countries: current policies, administration and guidelines. International Breast Cancer Screening Network (IBSN) and the European Network of Pilot Projects for Breast Cancer Screening. Int J Epidemiol 27: 735-742

Tabar L, Vitak B, Chen HH, Duffy SW, Yen MF, Chiang CF, Krusemo UB, Tot T, Smith RA (2000) The Swedish Two-County Trial twenty years later. Updated mortality results and new insights from long-term followup. Radiol Clin North Am 38: 625-651

The Breast Screening Frequency Trial Group (2002) The frequency of breast cancer screening: results from the UKCCCR Randomised Trial. Eur J Cancer 38: $1458-1464$ 